\title{
Minute Times Millimole per Milliliter
}

National Cancer Institute

\section{Source}

National Cancer Institute. Minute Times Millimole per Milliliter. NCI Thesaurus. Code C85730.

Minutes times millimoles per milliliter. 